\title{
The Effect of Pre-Operative Warming in Preventing Hypothermia and Shivering in Patients for Lower Limb Surgery under Subarachnoid Block
}

\author{
Ashfal Muhammed ${ }^{1}$, Sudhir N. ${ }^{2}$, Juby E.V. ${ }^{3}$, Sunilkumar T.S. ${ }^{4}$ \\ 1,2,3,4 Department of Anaesthesiology, Government Medical College, Thrissur, Kerala, India.
}

\section{ABSTRACT}

\section{BACKGROUND}

Subarachnoid block (SAB) is a versatile regional anaesthesia technique for lower limb surgeries. Hypothermia (shivering) is a frequent, potentially serious event after spinal anaesthesia which can lead to severe complications. Several methods are used to minimize perioperative hypothermia and shivering.

\section{METHODS}

A hospital based prospective study was conducted in Government Medical College, Thrissur, over 12 months from January 2019 to January 2020. 260 American Society of Anesthesiologists physical status I and II patients undergoing elective surgeries under spinal anaesthesia were included. Prior to surgery patients were randomly allotted into two groups; Group 1 and Group 2. Group 1 patients were pre-warmed for 20 minutes and Group 2 were not pre-warmed. Measurement of body temperature, vital signs and shivering score was taken peri-operatively. Occurrence of hypothermia and shivering was observed intraoperatively and one hour postoperatively.

\section{RESULTS}

Baseline demographic data of the 2 groups was comparable. Temperature was persistently lower at all points except baseline in Group 2 compared to Group 1. Of those pre-warmed, $4.6 \%$ and amongst those not pre-warmed, $65.4 \%$ had shivering. Difference is statistically significant with chi square of 105.5 and $p$ value $<.001$.

\section{CONCLUSIONS}

Incidence of hypothermia and shivering is found to be less in the pre-warmed. Hence, forced pre-warming has significant influence on hypothermia and shivering.

\section{KEY WORDS}

Subarachnoid Block, Pre-Warming, Hypothermia, Shivering.
Corresponding Author:

Dr. Sudhir N.,

Assistant Professor

Department of Anaesthesiology,

Government Medical College,

Thrissur- 680596, Kerala, India.

E-mail: jyothypsudhir@gmail.com

DOI: $10.14260 /$ jemds $/ 2022 / 1$

How to Cite This Article:

Muhammed A, Sudhir N, Juby EV, et al. The effect of pre-operative warming in preventing hypothermia and shivering in patients for lower limb surgery under subarachnoid block. J Evolution Med Dent Sci 2022;11(01):1-6, DOI: $10.14260 / \mathrm{jemds} / 2022 / 1$

Submission 02-12-2021,

Peer Review 14-12-2021,

Acceptance 31-12-2021,

Published 05-01-2022.

Copyright (C) 2022 Ashfal Muhammed et al. This is an open access article distributed under Creative Commons Attribution License [Attribution 4.0 International (CC BY 4.0)] 


\section{BACKGROUND}

Neuraxial anaesthesia as an alternative to general anaesthesia greatly adds to the anaesthesiologist's arsenal. Regional anaesthesia (spinal anaesthesia) is used as a safe technique for elective and emergency anaesthetics. Neuraxial techniques are safe when well managed. However, complications like self-limited back soreness, post dural puncture headache, debilitating permanent neurologic deficit or even death can still occur, albeit rarely.

Humans are homeothermic, requiring a near-constant internal body temperature. ${ }^{1}$ When internal temperature deviates significantly from normal, metabolic functions deteriorate, and death results. The thermoregulatory system maintains core body temperature within tenths of a degree of "normal," which is approximately $37^{\circ} \mathrm{C}$ in humans. ${ }^{2}$

In $40-70 \%$ patients undergoing regional anaesthesia shivering is an event, making it fairly frequent. ${ }^{3}$ Prolonged impairment of thermoregulatory autonomic control under anaesthesia along with cold operating room environment and infusion fluids, contribute to fall in core body temperature causing shivering. Other known causes include transfusion and drug reactions, pre-existing high-grade fever or bacteraemia or infusion of contaminated intravenous fluids.

Shivering is a serious event, causing an increase: in metabolic rate, oxygen consumption, carbon dioxide $\left(\mathrm{CO}_{2}\right)$ production, ventilation and cardiac output - leading to adverse postoperative outcomes. Shivering during anaesthesia can be controlled by non-pharmacological and pharmacological methods. Forced air pre-warming is a nonpharmacological method to decrease perioperative hypothermia and shivering.

Perioperative hypothermia is a common thermal disturbance while giving anaesthesia. Every patient undergoing surgery is at risk of developing it perioperatively due to reasons like evaporative heat loss from open body cavities, exposure to cold in preoperative and surgical suites, reduced metabolic heat production (no muscular activity), room-temperature antimicrobial skin preparations and IV fluids, cold operating room beds or various pharmacological agents. When internal body temperature deviates significantly from normal, metabolic functions deteriorate, resulting in serious complications. The thermoregulatory system maintains core body temperature within $0.2^{\circ} \mathrm{C}$ of normal, i.e. $\sim 37^{\circ} \mathrm{C}$. Prolonged impairment of thermoregulatory autonomic control under anaesthesia along with cold operating room ambient temperatures and infusion fluids, contribute to a fall in core temperature.

Incidence of postoperative hypothermia ranges from $26 \%$ to $90 \%$ in patients undergoing elective surgery. ${ }^{4}$ Consequences of hypothermia are both physiological and psychological, causing more problems than just a mere unpleasant experience of patients feeling 'cold'. Perioperative hypothermia causes several complications like shivering, thermal discomfort, coagulopathy, increased transfusion requirement, delayed drug metabolism, increased risk of surgical site infection, tissue ischemia, delayed wound healing etc. Also, it reduces patient satisfaction and prolongs hospital stay, increasing hospital costs. Understanding normal and anaesthetic drug influenced-thermoregulation helps prevention and management of such complications. Although shivering as a consequence of perioperative hypothermia is rarely the most serious, it is fairly frequent and remains poorly understood. Shivering is potentially a serious event, causing increased metabolic rate -- oxygen consumption is increased by $200 \%-500 \%$ along with a linear increase in carbon dioxide $\left(\mathrm{CO}_{2}\right)$ production, ventilation and cardiac output -- and adverse postoperative outcomes. Hypothermia triggers vasoconstriction and increases vascular resistance. Thus, in somebody with an already limited myocardial oxygen supply, shivering further compromises myocardial function.

Treatment and prevention are key factors in reducing incidence of hypothermia. Various methods available to control shivering during anaesthesia include nonpharmacological and pharmacological. Maintaining normothermia during perioperative period results in reduced hospital costs, decreased intraoperative bleeding, faster recovery, lower infection rates, and better thermal comfort, ultimately resulting in higher patient satisfaction.

A study by L Reynolds et al. $^{5}$ showed that mild perioperative hypothermia results in derangement of myocardial energetics and adverse myocardial outcomes in high-risk patients. Mild hypothermia significantly increases blood loss, augments allogenic transfusion requirements and increases incidence of surgical wound infection. Mild perioperative hypothermia also changes the kinetics and action of various anaesthetic and paralyzing agents, increases thermal discomfort and precipitates delayed post-anaesthetic recovery.

A study by Fatma Kavak Akelma et al. ${ }^{6}$ demonstrated that perioperative forced-air warming preserved core body temperature, reduced incidence of hypotension during induction, increased thermal comfort and improved satisfaction in TURP patients, but did not decrease shivering.

A study by J. Andrzejowski et al.7 on 'effect of prewarming on core temperature after induction and perioperative hypothermia occurrence in general anaesthesia patients showed a lesser decrease in mean core temperature and temperature maintained above the hypothermic threshold of $36^{\circ} \mathrm{C}$, in the prewarmed group.

In a study by Melissa Bucci Adriani et al..$^{8}$ on 'preoperative forced-air warming combined with intraoperative warming versus intraoperative warming alone in prevention of hypothermia during gynaecologic surgery' in 30 patients showed preoperative warming with the Bair Paws gown offered no benefit over conventional therapy in maintaining normothermia in perioperative period.

A randomized control trial in 200 patients by E-P Horn ${ }^{9}$ : 'The effect of short time periods of pre-operative warming in prevention of peri-operative hypothermia' showed significant differences in core temperature changes between the nonpre-warmed and all pre-warmed groups and summarized that pre-warming of patients for only 10-20 min before general anaesthesia mostly prevents hypothermia, reducing shivering.

The randomized trial of pre-warming by Melling and colleagues $^{10}$ involving more than 400 patients was powered to look for differences in postoperative complications and showed a significant decrease in postoperative wound infections in pre-warmed patients. However, incidence of perioperative hypothermia was not actually different between the groups. The authors postulated that prewarming improved peripheral circulation in the preoperative 
period, thus increasing tissue oxygenation and the protective effect of this increased tissue partial pressure of oxygen may persist in the postoperative period of shorter surgeries.

The study by Vanni and colleagues $^{11}$ showed an impressive effect of pre-warming, but was flawed both by inadequate power and by having a control group that was significantly hypothermic before anaesthetic induction.

Hirvonen and Niskanen ${ }^{12}$ tested the thermal suit in a previous study of patients in regional anaesthesia with a control group wearing hospital clothing, where both groups received active warming if the patient felt cold or the temperature dropped below $35.0^{\circ} \mathrm{C}$. They found that with the use of the thermal suit, significantly less hypothermia occurred in the post-anaesthesia care unit.

Kim et al. ${ }^{13}$ assessed the effectiveness of cutaneous warming during anaesthesia preparation on temperature and hemodynamic variables in early operative period in patients undergoing off-pump coronary artery bypass surgery and found that MAP values remained within normal range at preinduction period in warmed patients but not in the unwarmed.

The objective of the present study is to identify a simple and cost-effective method like preoperative warming to prevent perioperative hypothermia and shivering for a better patient outcome.

\section{METHODS}

This prospective study entitled "The effect of preoperative warming in preventing hypothermia and shivering in patients for lower limb surgery under subarachnoid block" was done over a period of 12 months in the Department of Anaesthesiology, Government Medical College, Thrissur, Kerala, India, from January 2019 to Jan 2020. This was undertaken after obtaining ethical committee clearance and an informed consent from all participants. Patients in age group of 18 - 60 years of either sex of ASA physical status grade I \& II were included in this study. Patients with fever, body mass index (BMI) more than $30 \mathrm{~kg} / \mathrm{m}^{2}$, history of convulsions, thyroid disorder, known psychiatric or musculoskeletal disorders were excluded. "The effect of short time periods of pre-operative warming in the prevention of peroperative hypothermia" by EP Horn, B Bein et al. was taken as the reference study to calculate the sample size for $5 \%$ level of significance and $80 \%$ power using the equation.

$N=\frac{\sqrt{2 p q \times 1.96}+\sqrt{p_{1} q_{1}}+\sqrt{p_{2} q_{2} \times 0.84}}{d^{2}}$

Where, $\mathrm{p}$ is the average, i.e. $\frac{p 1+p 2}{2}$

$\mathrm{p}_{1}$ is the proportion of the effect in the first group,

$\mathrm{p}_{2}$ is the proportion of the effect in the second group,

$\mathrm{q}_{1}$ is $(100-\mathrm{p})$,

$\mathrm{q}_{2}$ is $\left(100-\mathrm{p}_{2}\right)$ and

$\mathrm{d}$ is the precision / maximum variability we can afford.

As per the formula, sample size was taken as 130 in each group. ${ }^{9}$

A pre-anaesthetic check-up with a detailed history of present condition, co-morbidities, previous surgical history, proper general and systemic examinations and airway assessment was done. Informed written consent was obtained for participation in the study. Minimum 8 hours fasting for solid food was ensured before giving anaesthesia. Patients were grouped into one of two study groups by anaesthesia medical officer in charge: an active warming group or a control group. The first 130 patients who fulfilled the inclusion criteria were included for pre-operative warming and the subsequent number, in the second group. Patients were included according to the discretion of the duty anaesthesiologist and the investigators had no say in the matter. Throughout the study period the preoperative holding area, operating room and post anaesthesia care unit were maintained at a temperature of $22-24^{\circ} \mathrm{C}$. Baseline axillary temperature readings was obtained for all patients in preoperative holding area. Patients in active warming group received 20 minutes active warming with forced-air blanket set at $43^{\circ} \mathrm{C}$, placed over entire body. Following this warming period, forced-air blanket was removed and patient transferred to operating room. Patients in the non-prewarming group (Group 2) were only covered with bed sheet. Spinal anaesthesia was administered in operating room, all patients receiving hyperbaric bupivacaine. After spinal anaesthetic was performed, patients in both groups $1 \& 2$ were covered with standard double layer bed sheet over upper half of body and given warm IV fluids. Similar to baseline body temperature, vital signs and shivering scores recorded on arrival in pre-operative holding area. Measurements were taken on arrival in operating room, immediately after induction of spinal anaesthesia and every 10 min throughout surgery and 1 hour postoperatively.

Rescue medication for shivering was IV pethidine 0.5$1 \mathrm{mg} / \mathrm{kg}$. Active warming and IV pethidine were given even in absence of shivering if patient complained of thermal discomfort. Self-made proforma was filled up to document patient information, pre-anaesthetic check-up details, intraoperative monitoring and grade of shivering if any. Thermometers, pulse oximeters, multi parameter and ECG monitors were used.

Grades of shivering.

Grade 0 - No shivering

Grade 1 - pilo-erection/ peripheral vasoconstriction but no visible shivering.

Grade 2 - muscular activity in only 1 muscle group;

Grade 3 - muscular activity in $>1$ muscle group but not generalized.

Grade 4 - shivering involving whole body

Grade 2 shivering was considered significant

\section{Statistical Analysis}

Data was entered in Microsoft Excel software, and analysed using STATA software version 12 (manufactured by StataCorp LP, College Station, Texas).

In both groups continuous variables like age, height, weight and BMI were summarized as mean and standard deviation. ASA category summarized as proportions between both groups.

Body temperature at different time points summarized as mean with SD. Presence of significant shivering, need for active warming and IV pethidine summarized as proportions. Association between body temperature at different time points and groups was tested using unpaired $t$ - test. 
Association between categorical variables and pre-warming was assessed using chi square test.

\section{RESULTS}

The results are presented under socio demographic characteristics and outcome analysis.

\begin{tabular}{|ccccc|}
\hline \multirow{4}{*}{ Age } & Group 1 & Mean & SD & P Value \\
& Group 2 & 45.52 & 8 & 0.60 \\
Weight & Group 1 & 66.04 & 8.3 & \\
& Group 2 & 66.22 & 6.0 & 0.86 \\
\multirow{2}{*}{ Height } & Group 1 & 166.48 & 7.6 & \multirow{2}{*}{0.86} \\
& Group 2 & 166.34 & 5.9 & \\
BMI & Group 1 & 23.97 & 2.1 & \multirow{2}{*}{0.88} \\
& Group 2 & 24.02 & 2.6 & \\
\hline & Table 1. Socio Demographic Characteristics \\
\hline
\end{tabular}

The age of participants ranged from 31 to 59 years. And the groups were comparable when the age was compared using unpaired t-test with $p$ value 0.60 . The weight of participants was not significantly different between the groups with $\mathrm{p}$ value 0.86 . The height of participants was not significantly different between the groups with $p$ value 0.86 . The BMI of participants was not significantly different between the groups with $\mathrm{p}$ value 0.88 .

\begin{tabular}{|ccc|}
\hline ASA PS & $\begin{array}{c}\text { Number of Participants, } \mathbf{n}(\%) \\
\text { Group 1 }\end{array}$ & Group 2 \\
1 & $96(73.85)$ & $95(73.08)$ \\
2 & $34(26.15)$ & $35(26.92)$ \\
\hline \multicolumn{2}{|c|}{$\chi^{2}=\mathbf{0 . 0 2}$, p value =.89 } \\
\hline Table 2. Distribution of ASA PS Grade within Each Group \\
\hline
\end{tabular}

There was no significant difference in the distribution of ASA categories between the two arms ( $p$ value $=.89$ ).

\section{Outcome Analysis}

\begin{tabular}{|cccc|}
\hline & Group 1 & Group 2 & P Value \\
Baseline & $36.9(0.2)$ & $36.9(0.2)$ & .77 \\
T2 & $37.7(0.4)$ & $36.7(0.2)$ & $<.001$ \\
T3 & $36.6(0.3)$ & $35.4(0.4)$ & $<.001$ \\
T4 & $36.1(0.4)$ & $34.8(0.2)$ & $<.001$ \\
\hline Table 3. Body Temperature at Different Time Points between the \\
Groups
\end{tabular}

Temperature was persistently lower at all points except baseline in the Group 2 compared to Group 1. At baseline body temperature was comparable between the groups with $\mathrm{p}$ value.77.

\begin{tabular}{|ccc|}
\hline Peri-op Shivering & Number of Participants, n (\%) \\
Significant & Group 1 & Group 2 \\
Non-significant & $6(4.6)$ & $85(65.4)$ \\
& $124(95.4)$ & $45(34.6)$ \\
\hline Table 4. Incidence of Peri-operative Shivering \\
\hline
\end{tabular}

There was increased incidence of significant peri-op shivering in Group 2 and the difference was statistically significant with chi square of 105.5 and $p$ value <.001.

\begin{tabular}{|ccc|}
\hline Active Warming & \multicolumn{2}{c|}{ Number of Participants, n (\%) } \\
Group 1 & Group 2 \\
Yes & $12(9.2)$ & $109(83.8)$ \\
No & $118(90.8)$ & $21(16.2)$ \\
\multicolumn{3}{|c|}{$\chi^{2}=145.4$, p value $<.001$} \\
\hline \multicolumn{2}{|c|}{ Table 5. Need for Active Warming } \\
\hline
\end{tabular}

There was increased need of active warming in Group 2 and the difference was statistically significant with chi square of 145.4 and $p$ value $<.001$.

\begin{tabular}{|ccc|}
\hline IV Pethidine Need & Number of Participants, $\mathbf{n}(\%)$ \\
& Group 1 & Group 2 \\
Yes & $6(4.6)$ & $86(66.2)$ \\
No & $124(95.4)$ & $44(33.8)$ \\
\multicolumn{2}{|c|}{$\chi^{2}=107.7$, p value $<.001$} \\
\hline \multicolumn{2}{|c|}{ Table 6. Need for IV Pethidine } \\
\hline
\end{tabular}

There was increased need for IV pethidine in Group 2 and the difference was statistically significant with chi square of 107.7 and $p$ value $<.001$.

\section{DISCUSSION}

Hypothermia during anaesthesia is the most common perioperative thermal disturbance and is preventable. Every patient undergoing surgery is at risk of developing perioperative hypothermia due to decreased core body temperature. Prolonged impairment of thermoregulatory autonomic control under anaesthesia along with cold operating room environs and infusion fluids, contribute to fall in core body temperature. One complication of hypothermia is shivering which adversely affects patient outcome. This study was intended to find the effect of preoperative warming in preventing hypothermia and shivering.

Baseline demographic data of 2 groups were comparable. Mean age for Group 1 was 45.52 years with standard deviation of 8 and Group 2 was 46.04 years with SD of 8.3 . The $\mathrm{p}$ value of 0.6 was not statistically significant. Mean weight for Group 1 was $66.34 \mathrm{~kg}$ with SD 6.0 and Group 2 was $66.22 \mathrm{~kg}$ with SD 5.6. p value calculated 0.86 was not significant statistically. Mean height for Group 1 was $166.48 \mathrm{~cm}$ with SD 7.2 and Group 2, $166.34 \mathrm{~cm}$ with SD 5.9 . The $\mathrm{p}$ value 0.86 had no significance statistically. Chances of confounding in terms of age, weight and height were thus excluded. Temperature was persistently lower at all points except baseline in Group 2 compared to Group 1. At baseline, temperature was comparable between the groups with $p$ value 0.77 . Out of those pre-warmed, $4.6 \%$ and among those who were not, $65.4 \%$ had shivering. This difference was statistically significant with chi square of 105.5 and $p$ value $<001$. $83.8 \%$ of Group 2 needed active warming while only $9.2 \%$ of Group 1 needed it. $4.6 \%$ patients needed IV pethidine for shivering in Group 1 while $66.2 \%$ of Group 2 patients needed it, which was statistically significant with chi square of 107.7 and $p$ value $<001$.

Result of our study were comparable to the Jun J et al. study which showed use of pre-anaesthetic active warming with a forced-air warmer in combination with pre-warmed IV fluids effective in reducing rates of maternal hypothermia and shivering. ${ }^{14}$

The study by FK Akelma et al. demonstrated that perioperative forced-air warming preserved perioperative core body temperature, reduced incidence of hypotension during the induction period, increased thermal comfort and improved patient satisfaction, but did not affect shivering in patients undergoing TURP surgery under general anaesthesia. 
Hypothermia causes reduction in splanchnic blood flow and suppression of liver function, prolonging the action of anaesthetic drugs like pancuronium, and morphine, which depend on the metabolic or excretory functions of the liver. ${ }^{15}$

Patients with intraoperative hypothermia have a higher serum concentration of norepinephrine, more intense peripheral vasoconstriction and also higher arterial pressures in the early postoperative period. 16

When compared to normothermic patients, patients with intraoperative hypothermia had a threefold higher incidence of myocardial ischemia on ECG and a 12 -fold increase of angina postoperatively in another study. ${ }^{17}$ These findings lend more credence for pre-warming to reduce the incidence of hypothermia and shivering in patients under subarachnoid block.

The randomized trial of pre-warming by Melling and colleagues involving more than 400 patients was powered to look for differences in postoperative complications and showed a significant decrease in postoperative wound infections in pre-warmed patients. However, incidence of perioperative hypothermia between the groups was no different.

In a landmark study in 1987, evaluating the effect of local hyperthermia on subcutaneous oxygen tension and blood flow, Rabkin and Hunt had found a linear correlation between subcutaneous tissue temperature and oxygen tension. ${ }^{18}$ The authors postulated that pre-warming improved peripheral circulation in the preoperative period, thus increasing tissue oxygenation. It is suggested that this protective effect of increased tissue partial pressure of oxygen would last into the postoperative period in short-duration surgery.

\section{CONCLUSIONS}

Our study was to gauge the effect of preoperative warming in preventing hypothermia and shivering in patients undergoing lower limb surgery under lumbar subarachnoid block. From this study we found that 20 minutes of warming in the preoperative period reduces the rate of temperature reduction, decreases perioperative shivering, increases thermal comfort and improves patient satisfaction.

\section{Limitations}

The inclusion criteria of an age group of $18-60$ years includes people in the geriatric age who are inherently vulnerable to hypothermia. Also, some patients who complained of feeling cold and requested warming measures were actively warmed even without shivering. Thus, in Group 1 , only $6(4.6 \%)$ patients had significant shivering but we actively warmed $12(9.2 \%)$ and in Group 2, 85 (65.4\%) patients had significant shivering but $109(83.8 \%)$ were given active warming on demand.

Data sharing statement provided by the authors is available with the full text of this article at jemds.com.

Financial or other competing interests: None.

Disclosure forms provided by the authors are available with the full text of this article at jemds.com.

\section{REFERENCES}

[1] Sessler DI. Temperature monitoring: the consequences and prevention of mild perioperative hypothermia. Southern African Journal of Anaesthesia and Analgesia 2014; 20(1):25-31.

[2] Sessler DI. Thermoregulatory defense mechanisms. Crit Care Med 2009;37(7 Suppl):203-10.

[3] Shukla U, Malhotra K, Prabhakar T. A comparative study of the effect of clonidine and tramadol on post-spinal anaesthesia shivering. Indian J Anaesth 2011;55(3):2426.

[4] Moola S, Lockwood C. Effectiveness of strategies for the management and/or prevention of hypothermia within the adult perioperative environment. Int J Evid Based Health 2011;9(4):337-45.

[5] Reynolds L, Beckmann J, Kurz A. Perioperative complications of hypothermia. Best Pract Res Clin Anaesthesiol 2008;22(4):645-57.

[6] Akelma FK, Ergil J, Özkan D, et al. The effect of preoperative warming on perioperative hypothermia in transurethral prostatectomies. Gülhane Tip Dergisi 2020;62(2):114.

[7] Andrzejowski J, Hoyle J, Eapen G, et al. Effect of prewarming on post-induction core temperature and the incidence of inadvertent perioperative hypothermia in patients undergoing general anaesthesia. $\mathrm{Br} \mathrm{J}$ Anaesth 2008;101(5):627-31.

[8] Adriani MB, Moriber N. Preoperative forced-air warming combined with intraoperative warming versus intraoperative warming alone in the prevention of hypothermia during gynecologic surgery. AANA J 2013;81(6):446-51.

[9] Horn EP, Bein B, Böhm R, et al. The effect of short time periods of pre-operative warming in the prevention of peri-operative hypothermia. Anaesthesia 2012;67(6):612-7.

[10] Melling AC, Ali B, Scott EM, et al. Effects of preoperative warming on the incidence of wound infection after clean surgery: a randomized controlled trial. Lancet 2001;358(9285):876-80.

[11] Vanni SMDA, Braz JRC, Módolo NSP, et al. Preoperative combined with intraoperative skin-surface warming avoids hypothermia caused by general anaesthesia and surgery. J Clin Anesth 2003;15(2):119-25.

[12] Hirvonen EA, Niskanen $M$. Thermal suits as an alternative way to keep patients warm peri-operatively: a randomised trial. Eur J Anaesthesiol 2011;28(5):37681.

[13] Kim JY, Shinn H, Oh YJ, et al. The effect of skin surface warming during anaesthesia preparation on preventing redistribution hypothermia in the early operative period of off-pump coronary artery bypass surgery. Eur I Cardiothorac Surg 2006;29(3):343-7.

[14] Jun JH, Chung MH, Jun IJ, et al. Efficacy of forced-air warming and warmed intravenous fluid for prevention of hypothermia and shivering during caesarean delivery under spinal anaesthesia: a randomized controlled trial. Eur J Anaesthesiol 2019;36(6):442-8. 
[15] Hallet EB. Effect of decreased body temperature on liver function and splanchnic blood flow in dogs. Surg Forum 1954;5:362-5.

[16] Frank SM, Higgins SM, Breslow JM et al. The catecholamine, cortisol and hemodynamic responses to mild perioperative hypothermia: a randomised clinical trial. Anesthesiology 1995;82(1):83-93.
[17] Frank SM, Beattie C, Christopherson R, et al. Unintentional hypothermia is associated with postoperative myocardial ischemia. The Perioperative Ischemia Randomized Anaesthesia Trial Study Group. Anesthesiology 1993;78(3):468-76.

[18] Rabkin JM, Hunt TK. Local heat increases blood flow and oxygen tension in wounds. Arch Surg 1987;122(2):2215. 